\title{
PILE LOAD CAPACITY - CALCULATION METHODS
}

\author{
BOGUMIL WRANA \\ Civil Engineering Department, Institute of Structures Mechanics, Soil-Structure-Interaction Branch, \\ Cracow University of Technology, Warszawska 24, 31-155 Kraków, Poland, \\ e-mail:wrana@limba.wil.pk.edu.pl
}

\begin{abstract}
The article is a review of the current problems of the foundation pile capacity calculations. The article considers the main principles of pile capacity calculations presented in Eurocode 7 and other methods with adequate explanations. Two main methods are presented: $\alpha$-method used to calculate the short-term load capacity of piles in cohesive soils and $\beta$-method used to calculate the long- term load capacity of piles in both cohesive and cohesionless soils. Moreover, methods based on cone CPTu result are presented as well as the pile capacity problem based on static tests.
\end{abstract}

Key words: pile load capacity calculation, Eurocode 7, $\alpha$-method and $\beta$-method, direct methods based on CPTu data

\section{INTRODUCTION}

Piles can be either driven or cast in place. Pile driving is achieved by: impact dynamic forces from hydraulic and diesel hammers; vibration or jacking. Concrete and steel piles are most common. Driven piles which tend to displace a large amount of soil due to the driving process are called full-displacement piles. Cast-in-place (or bored) piles do not cause any soil displacement, therefore, they are non-displacement piles.

Piles may be loaded axially and/or transversely. The limit states necessary to be considered in the design of piles are the following (EN-1997-1, $\S 7.2 .(1) \mathrm{P})$ :

- Bearing resistance failure of the pile foundation,

- Insufficient compression resistance of the pile (Fig. 1a),

- Uplift or insufficient tensile resistance of the pile (Fig. 1d),

- Failure in the ground due to transverse loading (Fig. 1f),

- Structural failure of the pile in compression (Fig. 1b), tension (Fig. 1e), bending (Fig. 1g), buckling (Fig. 1c) or shear (Fig. 1h),

- Combined failure in the ground, in the pile foundation and in the structure,

- Excessive settlement, heave or lateral movement,

- Loss of overall stability,

- Unacceptable vibrations.
The pile load capacity on compression (Fig. 1a-1c) is considered in the article, in particular the sufficient compressing resistance case (Fig. 1a).

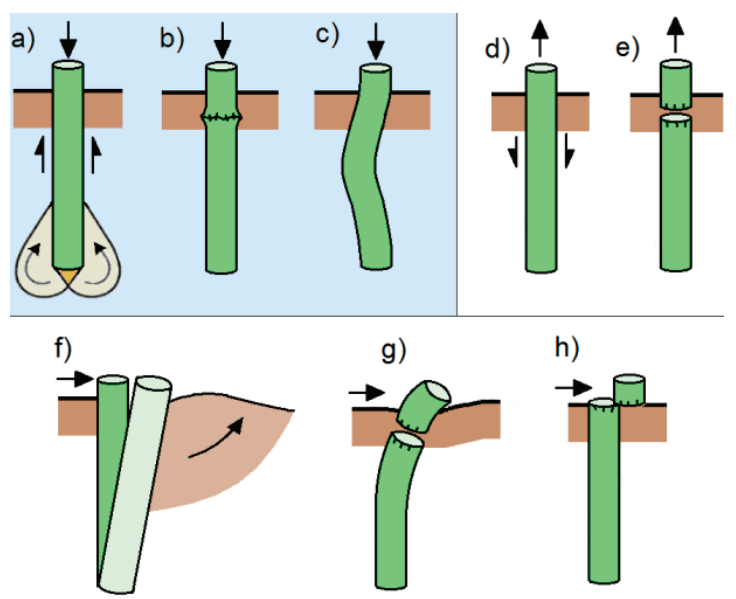

Fig. 1. Piles load capacity:

(a)-(c) on compression, (d), e) on tension, (f)-(h) on transverse loading

Figure 2a shows the following main parameters used in the pile capacity problem:

- $s(Q)$ - load-settlement top pile data recorded in the in-situ test on compression,

- $s_{k}$ - characteristic settlement, generally calculated using the assumption on soil behavior as: semiinfinite elastic, isotropic and homogenous area (Boussinesq theory), which gives such larger settlement than the measured one, 
- $R_{c ; d}$ - design resistance as the capacity parameters determined from designing standards, considered in the present article,

- $R_{\text {test }}-$ in-situ static test result on top pile,

- $Q_{\text {lim }}-$ limit resistance defined as rapid settlement occurs under sustained or slight increase of the applied load - the pile plunges. factor.

Ration of $Q_{\lim } / R_{c ; d}=\gamma_{t}$ presents the total safety

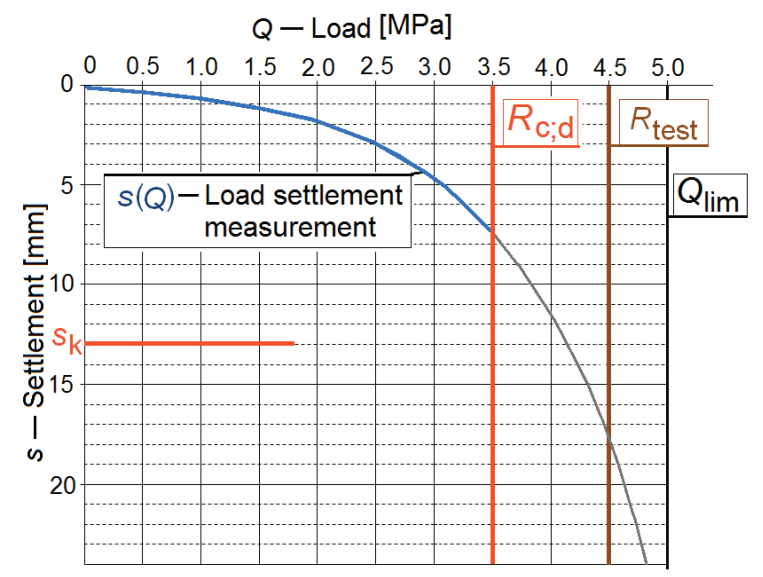

Fig. 2a. Capacity parameters:

$R_{c ; d}$ - design resistance, $R_{\text {test }}-$ static test result,

$Q_{\text {lim }}-$ limit resistance, $s(Q)$ - load-settlement curve

from top pile measurement $s_{k}$-characteristic settlement

Figure $2 \mathrm{~b}$ shows typical load/settlement curves for compressive load of the shaft $Q_{s}$ and the base $Q_{b}$ load capacity and the total load capacity $Q_{t}$ characteristic depending on soil layers: (a) for friction pile and (b) for end-bearing pile.
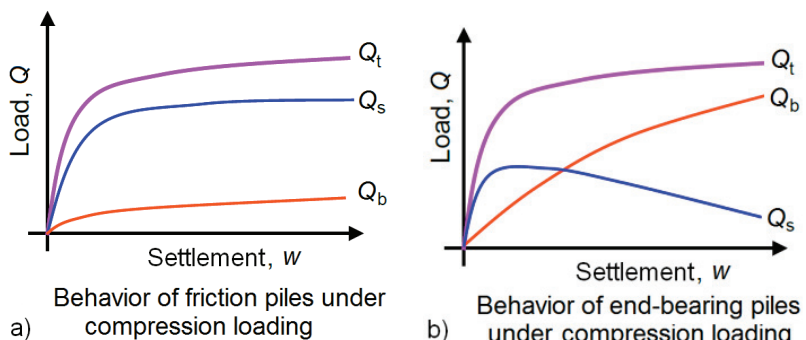

Fig. 2b. Typical load/settlement curves for compressive load tests: (a) friction pile; (b) end-bearing pile

\section{APPROACHES OF PILE DESIGN ACC. TO EN-1997}

EN 1997-1 \$7.4(1)P states that the design of piles shall be based on one of the following approaches:
(1) The results of static load tests, which have been demonstrated by means of calculations or otherwise, to be consistent with other relevant experience,

(2) Empirical or analytical calculation methods whose validity has been demonstrated by static load tests in comparable situations,

(3) The results of dynamic load tests whose validity has been demonstrated by static load tests in comparable situations,

(4) The observed performance of a comparable piles foundation, provided that this approach is supported by the results of site investigation and ground testing.

\section{Equilibrium equation}

The equilibrium equation to be satisfied in the ultimate limit state design of axially loaded piles in compression is

$$
F_{c ; d} \leq R_{c ; d},
$$

where $F_{c ; d}$ is the design axial compression load and $R_{c ; d}$ is the pile compressive design resistance.

\section{Design axial load}

The design axial compressive load $F_{c ; d}$ is obtained by multiplying the representative permanent and variable loads, $G$ and $Q$ by the corresponding partial action factors $\gamma_{G}$ and $\gamma_{Q}$

$$
F_{c ; d}=\gamma_{G} G_{r e p}+\gamma_{Q} Q_{\text {rep }} .
$$

The two sets of recommended partial factors on actions and the effects of actions are provided in Table A3 of Annex A of EN 1997-1.

\section{Characteristic pile resistance}

Eurocode 7 describes three procedures for obtaining the characteristic compressive resistance $R_{c, k}$ of a pile:

(a) Directly from static pile load tests with coefficient $\xi_{1}$ and $\xi_{2}$ for $n$ pile load tests, given in Table A.9 of EN 1997-1 Annex A,

(b) By calculation from profiles of ground test results or by calculation from ground parameters with coefficient given in Table A.10 of EN 1997-1 Annex A,

(c) Directly from dynamic pile load tests with coefficientgiven in Table A.11 of EN 1997-1 Annex A.

In the case of procedures (a) and (b) Eurocode 7 provides correlation factors to convert the measured pile resistances or pile resistances calculated from profiles of test results into characteristic resistances. 
Case (c) is referred to as the alternative procedure in the Note to EN 1997-1 §7.6.2.3(8), even though it is the most common method in some countries.

\section{Characteristic pile resistance from profiles of ground test results}

Part 2 of EN 1997 includes the following Annexes with methods to calculate the compressive resistance, $R_{c, c a l}$ of a single pile from profiles of ground test results:

(a) D.6 Example to determine $R_{c ; c a l}$ based on cone penetration resistance: relating the pile's unit base resistances $q_{b}$ at different normalised pile settlements, $s / D$, and the shaft resistance $q_{s}$ to average cone penetration resistance $q_{c}$ values. The values in Tables D. 3 and D. 4 are used to calculate the pile base and shaft resistances in the pile.

(b) D.7 Example to determine $R_{c ; c a l}$ base on maximum base resistance and shaft resistance from the $q_{c}$ values obtained from an electrical CPT.

(c) E.3 Example to determine $R_{c ; c a l}$ based on results of an MPM test.

Characteristic total pile compressive resistance $R_{c ; k}$ or the base and shaft resistances $R_{b ; k}$ and $R_{s ; k}$ may be determined directly by applying correlation factors $\xi_{3}$ and $\xi_{4}$ to the set of pile resistances calculated from the test profiles. This procedure is referred to as the Model Pile procedure by Frank et al. (2004) to determine $R_{c ; c a l}$.

\section{Characteristic pile resistance \\ from the ground parameters}

The characteristic base and shaft resistances may also be determined directly from the ground parameters using the following equations given in EN 1997-1 $\S 7.6 .2 .3(8)$

$$
\begin{gathered}
R_{b ; k}=A_{b} \cdot q_{b ; k} \\
R_{s ; k}=\sum A_{s ; i} \cdot q_{s ; i ; k}
\end{gathered}
$$

where

$q_{b ; k}$ - characteristics of unit base resistance,

$q_{s ; i ; k}$ - characteristics of unit shaft resistance in the $i$-th layer.

\section{Design compressive pile resistance}

The design compressive resistance of a pile $R_{c ; d}$ may be obtained either by treating the pile resistance as a total resistance

$$
R_{c ; d}=\frac{R_{c ; k}}{\gamma_{t}}
$$

or by separating it into base and shaft components $R_{b ; d}$ and $R_{s ; k}$, using the relevant partial factors, $\gamma_{b}$ and $\gamma_{s}$

$$
R_{c ; d}=\frac{R_{b ; k}}{\gamma_{b}}+\frac{R_{s ; k}}{\gamma_{s}} .
$$

The combinations of sets of partial factor values that should be used for Design Approach 2 are as follows

$$
\text { DA2.C1: A1 “+” M1 “+” R2 }
$$

where R2 for base, shaft and total: $\gamma_{t}=\gamma_{b}=\gamma_{s}=1.1$ in case of compression, and $\gamma_{t}=1.15$ in case of shaft in tension.

\section{DRAINED AND UNDRAINED LOADING CONDITIONS}

Drained loading occurs when soils are loaded slowly, resulting in slightexcess pore pressures that dissipate due to permeability.On the other hand, undrained loading occurs when fine-grained soils are loaded at a high rate, they generate excess pore pressures because these soils have very low permeabilities.

The drained (or long-term) strength parameters of a soil, $c^{\prime}$ and $\phi^{\prime}$ must be used in drained (long-term) analysis of piles.

The undrained (or short-term) strength parameter of a soil, $c_{u}$, must be used in undrained (short-term) analysis of piles.

\section{ESTIMATING LOAD CAPACITY OF PILES}

Pile load carrying capacity depends on various factors, including: (1) pile characteristics such as pile length, cross section, and shape; (2) soil configuration and short and long-term soil properties; and (3) pile installation method. Two widely used methods for pile design will be described:

- $\quad \alpha$-method used to calculate the short-term load capacity (total stress) of piles in cohesive soils,

- $\beta$ - method used to calculate the long-term load capacity (effective stress) of piles in both cohesive and cohesionless soils.

Piles resist applied loads through side friction (shaft or skin friction) and end bearing as indicated in Fig. 3. Friction piles resist a significant portion of their loads by the interface friction developed be- 
tween their surface and the surrounding soils. On the other hand, end-bearing piles rely on the bearing capacity of the soil underlying their bases. Usually, end-bearing piles are used to transfer most of their loads to a stronger stratum that exists at a reasonable depth.

Design bearing capacity (resistance) can be defined as

$$
R_{c, d}=Q_{b}+Q_{s}=A_{b} \cdot q_{b}+\sum A_{s, i} \cdot q_{s ; i ; d} .
$$

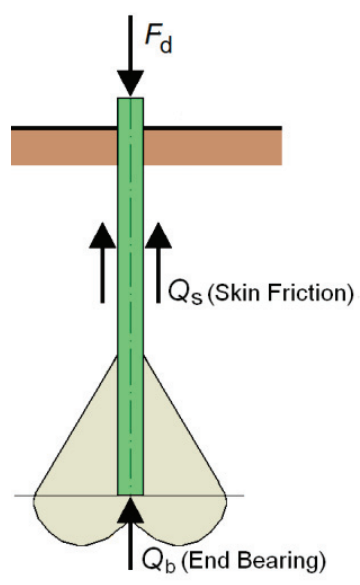

Fig. 3. Pile's side friction (shaftor skin friction) and end bearing

\section{5. $\alpha$-METHOD, SHORT-TERM LOAD CAPACITY FOR COHESIVE SOIL}

\subsection{UNIT SKIN FRICTION $q_{s}(z)$}

The method is based on the undrained shear strength of cohesive soils; thus, it is well suited for short-term pile load capacity calculations. In this method, the skin friction is assumed to be proportional to the undrained shear strength $s_{u}$, of the cohesive soil as follows and the interface shear stress $q_{s}$ between the pile surface and the surrounding soil is determined as

$$
q_{s}(z)=\alpha(z) s_{u}(z)
$$

where

$s_{u}$ - undrained shear strength,

$\alpha$ - adhesion coefficient depending on pile material and clay type.

It is usually assumed that ultimate skin friction is independent of the effective stress and depth. In reality, the skin friction is dependent on the effective stress and undrained shear strength but decreases for long piles.

Niazi and Mayne [24] presented 25 methods of estimating pile unit shaft resistance within $\alpha$-method and compared them. They showed main differences with respect to parameters: length effect, stress history, $I_{p}, s_{u}, \sigma_{v}^{\prime}$, progressive failure, plugging effect. Belowthe main methods estimating skin friction in claysare shown:

(a) American Petroleum Institute (API, 1984, 1987)

The equation by API $(1984,1987)$ suggests values for $\alpha$ as a function of $c_{u}$ as follows

$$
\alpha= \begin{cases}1-\frac{c_{u}-25}{90} & \text { for } 25 \mathrm{kPa}<c_{u}<70 \mathrm{kPa} \\ 1.0 & \text { for } c_{u} \leq 25 \mathrm{kPa} \\ 0.5 & \text { for } c_{u} \geq 70 \mathrm{kPa}\end{cases}
$$

(b) NAVFAC DM 7.2 (1984). Proposition for $\alpha$ coefficient depends on type of pile (Table 1)

Table 1. $\alpha$ vs. undrained shear strength (NAVFAC DM 7.2)

\begin{tabular}{|c|l|c|c|}
\hline \multirow{4}{*}{ Pile type } & \multicolumn{1}{|c|}{$\begin{array}{c}\text { Soil } \\
\text { consistency }\end{array}$} & $\begin{array}{c}\text { Undrained shear } \\
\text { strength } s_{u}[\mathrm{kPa}]\end{array}$ & $\alpha$ \\
\hline \multirow{4}{*}{$\begin{array}{c}\text { Timber and } \\
\text { concrete piles }\end{array}$} & Very soft & $0-12$ & 1.00 \\
\cline { 2 - 4 } & Soft & $12-24$ & $1.00-0.96$ \\
\cline { 2 - 4 } & Medium stiff & $24-48$ & $0.96-0.75$ \\
\cline { 2 - 4 } & Stiff & $48-96$ & $0.75-0.48$ \\
\cline { 2 - 4 } & Very stiff & $96-192$ & $0.48-0.33$ \\
\hline \multirow{5}{*}{ Steel piles } & Very soft & $0-12$ & 1.00 \\
\cline { 2 - 4 } & Soft & $12-24$ & $1.00-0.92$ \\
\cline { 2 - 4 } & Medium stiff & $24-48$ & $0.92-0.70$ \\
\cline { 2 - 4 } & Stiff & $48-96$ & $0.70-0.36$ \\
\cline { 2 - 4 } & Very stiff & $96-192$ & $0.36-0.19$ \\
\hline
\end{tabular}

As in the API method, effective stress effects are neglected in the DM 7.2 method.

(c) Equation based on undrained shear strength and effective vertical stress, Kolk and Van der Velde method [18]. Coefficient $\alpha$ is based on the ratio of undrained shear strength and effective stress. A large database of pile skin friction results was analyzed and correlated to obtain $\alpha$ value (Table 2).

(d) Simple rules to obtain coefficient $\alpha$ based on $s_{u} / \sigma_{v}^{\prime}$ proposed standard DNV-OS-J101-2007

$$
\alpha= \begin{cases}\frac{1}{2 \sqrt{s_{u} / \sigma_{v}^{\prime}}} & \text { or } s_{u} / \sigma_{v}^{\prime} \leq 1, \\ \frac{1}{2^{4} \sqrt{s_{u} / \sigma_{v}^{\prime}}} & \text { or } s_{u} / \sigma_{v}^{\prime}>1 .\end{cases}
$$


Table 2. Skin friction factor dependent on $s_{u} / \sigma_{v}^{\prime}$

\begin{tabular}{|c|c|c|c|c|c|c|c|c|c|c|c|c|c|}
\hline$s_{u} / \sigma_{v}^{\prime}$ & 0.2 & 0.3 & 0.4 & 0.5 & 0.6 & 0.7 & 0.8 & 0.9 & 1.0 & 1.1 & 1.2 & 1.3 & 1.4 \\
\hline$\alpha$ & 0.95 & 0.77 & 0.70 & 0.65 & 0.62 & 0.60 & 0.56 & 0.55 & 0.53 & 0.52 & 0.50 & 0.49 & 0.48 \\
\hline$s_{u} / \sigma_{v}^{\prime}$ & 1.5 & 1.6 & 1.7 & 1.8 & 1.9 & 2.0 & 2.1 & 2.2 & 2.3 & 2.4 & 2.5 & 3.0 & 4.0 \\
\hline$\alpha$ & 0.47 & 0.42 & 0.41 & 0.41 & 0.42 & 0.41 & 0.41 & 0.40 & 0.40 & 0.40 & 0.40 & 0.39 & 0.39 \\
\hline
\end{tabular}

(e) Mechanism controlling friction fatigue, Randolph [26]

Randolph [26] suggested that progressive failure, which occurs in strain softening soil, was a possible mechanism controlling friction fatigue. The progressive failure from the peak $\left(\tau_{\text {peak }}\right)$ to the residual $\left(\tau_{\text {res }}\right)$ shaft resistance is shown in Fig. 4. Randolph [26] proposed a reduction factor $\left(R_{f}\right)$ which depends on the degree of softening $\xi$ and the pile compressibility $K$

$$
R_{f}=1-(1-\xi)\left(1-\frac{1}{2 \sqrt{K}}\right)^{2}
$$

where

$$
\xi=\frac{\tau_{\text {res }}}{\tau_{\text {peak }}}, \quad K=\frac{\pi D L^{2} \frac{\tau_{\text {peak }}}{(E A)_{\text {pile }}}}{\Delta w_{\text {res }}},
$$

$E A$ - axial stiffnes of pile,

$\Delta w_{\text {res }}$ - post-peak displacement required to mobilize the residual shaft resistance.

(f) Norwegian Geotechnical Institute, NGI-05

Karlsrud et al. [15], proposed modification of the NGI method by introducing correlation of $s_{u d} / \sigma_{v 0}^{\prime}$ and $I_{p}$ with $\alpha$-coefficient presented by the trend lines shown in Fig. 4. New data are included herein, all previous data have been re-interpreted.

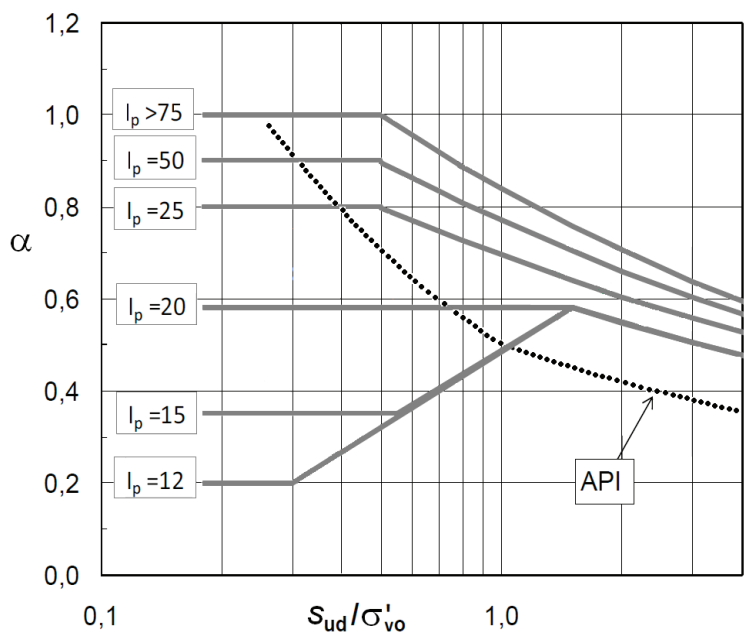

Fig. 4. Measured values of $\alpha$ in relation to normalized strength, for all piles (Karlsrud et al. [15])
Figure 4 presents mobilized values of $\alpha$ versus $s_{u d} / \sigma_{v 0}^{\prime}$ for all piles discussed in this paper. Studies have shown that the plasticity index has a largeimpact on the mobilized ultimate shaft friction and corresponding $\alpha$-values.

\subsection{UNIT BASE RESISTANCE $q_{B}$}

For cohesive soils it can be shown, using Terzaghi's bearing capacity equation, that the unit base resistance of the pile is

$$
q_{b}=\left(s_{u}\right)_{b} N_{c}
$$

where $\left(s_{u}\right)_{b}$ is the undrained shear strength of the cohesive soil under the base of the pile, and $N_{c}$ is the bearing capacity coefficient that can be assumed equal to 9.0 (Skempton [29]).

\section{6. $\beta$-METHOD, LONG-TERM LOAD CAPACITY FOR COHESIVE AND COHESIONLESS SOILS}

\subsection{UNIT SKIN RESISTANCE $q_{s}(z)$}

The method is based on effective stress analysis and is suited for long-term (drained) analyses of pile load capacity. The unit skin resistance $q_{s}$, between the pile and the surrounding soil is calculated by multiplying the friction factor, $\mu$, between the pile and soil by $\sigma_{h}^{\prime}$

$$
q_{s}(z)=\mu \sigma_{h}^{\prime}=\mu(z) K(z) \sigma_{v}^{\prime}(z)=\beta(z) \sigma_{v}^{\prime}(z)
$$

where at rest pressure coefficient depends on the installation mode, usually $K=K_{0}$, with $K_{0}=$ $\left(1-\sin \phi^{\prime}\right)(\mathrm{OCR})^{0.5} \leq 3$,

OCR - overconsolidation ratio,

$\sigma_{v}^{\prime}$ - vertical effective stress.

Niazi and Mayne [24] presented 15 methods of estimating pile unit shaft resistance within $\beta$-method and compared them. They showed main differences 
between them with respect to parameters: $\sigma_{r}^{\prime}, \delta, \phi^{\prime}$, OCR, $K, \sigma_{v}^{\prime}, L, d, s_{u}, I_{D}, I_{p}$. The main methods estimating skin frictionare shown below:

(a) according to NAVFAC DM 7.2(1984), $\beta=$ $\mu(z) K(z)=\tan \delta(z) K(z)$, Tables 3 and 4.

Table 3. Pile skin friction angle $(\delta)$

\begin{tabular}{|l|c|}
\hline Pile type & Pile-soil interface friction angle $(\delta)$ \\
\hline Steel piles & $20^{\circ}$ \\
\hline Timber piles & $3 / 4 \phi^{\prime}$ \\
\hline Concrete piles & $3 / 4 \phi^{\prime}$ \\
\hline
\end{tabular}

Table 4. Lateral earth pressure coefficient $(K)$

\begin{tabular}{|l|c|c|}
\hline \multicolumn{1}{|c|}{ Pile type } & $\begin{array}{c}K \text { (piles under } \\
\text { compression) }\end{array}$ & $\begin{array}{c}K \text { (piles } \\
\text { under tension) }\end{array}$ \\
\hline \multicolumn{1}{|c|}{ Driven H-piles } & $0.5-1.0$ & $0.3-0.5$ \\
\hline $\begin{array}{l}\text { Driven displacement piles } \\
\text { (round and square) }\end{array}$ & $1.0-1.5$ & $0.6-1.0$ \\
\hline $\begin{array}{l}\text { Driven displacement tapered } \\
\text { piles }\end{array}$ & $1.5-2.0$ & $1.0-1.3$ \\
\hline Driven jetted piles & $0.4-0.9$ & $0.3-0.6$ \\
\hline $\begin{array}{l}\text { Bored piles (less than } 60 \mathrm{~cm} \\
\text { in diameter) }\end{array}$ & 0.7 & 0.4 \\
\hline
\end{tabular}

(b) proposition value of $\beta=\mu(z) K(z)$ can be estimated according to the following propositions:

\begin{tabular}{|l|l|}
\hline \multicolumn{1}{|c|}{ Author } & \multicolumn{1}{|c|}{ Proposition of $\beta$ value } \\
\hline $\begin{array}{l}\text { McClelland [21] } \\
\text { for driven piles }\end{array}$ & $\begin{array}{l}\beta=0.15 \text { to } 0.35 \text { for compression, } \\
\beta=0.10 \text { to } 0.25 \text { for tension (for uplift piles) }\end{array}$ \\
\hline Meyerhof [22] & $\begin{array}{l}\beta=0.15,0.75,1.2 \text { for } \phi^{\prime}=28^{\circ}, 35^{\circ}, 37^{\circ}, \\
\text { for driven piles } \\
\beta=0.1,0.2,0.35 \text { for } \phi^{\prime}=33^{\circ}, 35^{\circ}, 37^{\circ}, \\
\text { for bored piles }\end{array}$ \\
\hline $\begin{array}{l}\text { Kraft and Lyons } \\
{[19]}\end{array}$ & $\begin{array}{l}\beta=C \tan \left(\phi^{\prime}-5\right) \\
C=0.7 \text { for compression, } C=0.5 \text { for tension } \\
\text { (uplift piles) }\end{array}$ \\
\hline
\end{tabular}

(c) Average $K$ method

Earth pressure coefficient $K$ can be averaged from $K_{a}, K_{p}$ and $K_{0}: K=\left(K_{0}+K_{a} K_{p}\right) / 3$ where: $K_{0}=(1-$ $\left.\sin \phi^{\prime}\right), K_{a}=\tan ^{2}\left(45-\phi^{\prime} / 2\right), K_{p}=\tan 2\left(45+\phi^{\prime} / 2\right)$

(d) Karlsrud [16]

Karlsrud [16] proposed to take into account the plasticity index $I_{p}$ in $\beta$-method. Figure 5 shows diagram of $\beta$-values from as low as 0.045 for lowplastic NC clays to about 2.0 to very stiff clays with OCR of 40 , which is the upper range of available pile data.

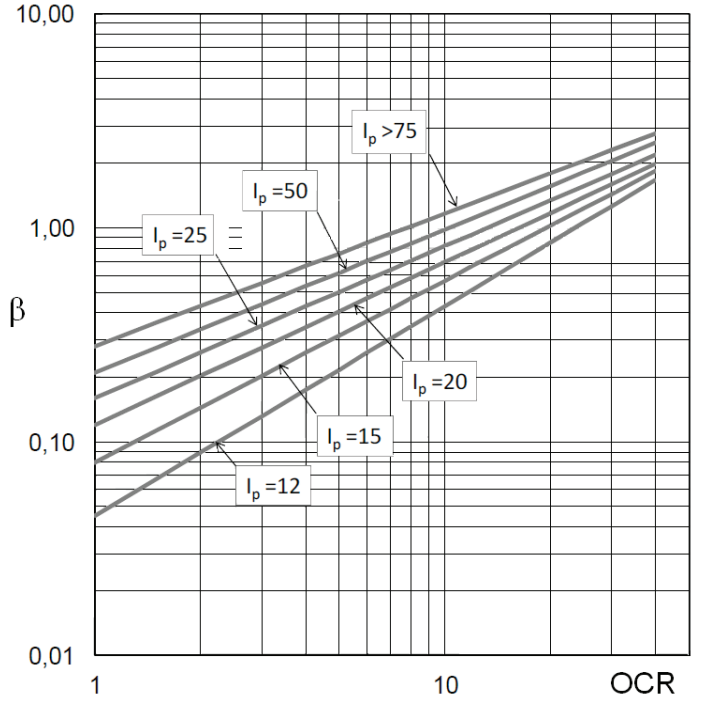

Fig. 5. Chart for determination of $\beta$-values dependent on OCR and $I_{p}$, Karlsrud [16]

\subsection{UNIT BASE RESISTANCE $q_{b}$}

Using Terzaghi's bearing capacity equation, the unit base resistance at the base of the pile can be calculated

$$
q_{b}=\left(\sigma_{v}^{\prime}\right)_{b} N_{q}+c_{b}^{\prime} N_{c}
$$

where

$\left(\sigma_{v}^{\prime}\right)_{b}$ - vertical effective stress at the base of the pile,

$c_{b}^{\prime}$ - cohesion of the soil under the base of the pile, $N_{c}=\left(N_{q}-1\right) \cot \phi^{\prime}$.

\section{Values of bearing capacity factor $N_{q}$}

(a) Janbu [13] presented equations to estimate capacity coefficients $N_{q}$ and $N_{c}$ for various soils

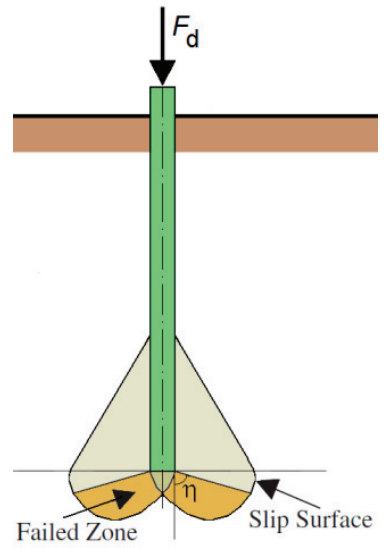

Fig. 6. Shear surface around the base of a pile: definition of the angle $\eta$ (Janbu [13]) 


$$
N_{q}\left(\tan \phi^{\prime}+\sqrt{1+\tan ^{2} \phi^{\prime}}\right)^{2} \exp \left(2 \eta \tan \phi^{\prime}\right)
$$

where $\eta$ is an angle defining the shape of the shear surface around the tip of a pile as shown in Fig. 6. The angle $\eta$ ranges from $\pi / 3$ for soft clays to $0.58 \pi$ for dense sands.

(b) Values of bearing capacity factor $N_{q}$ according to NAVFAC DM 7.2(1984), see Table 5. friction angle decreases with depth. Hence $N_{q}$, which is a function of the friction angle, also would reduce with depth. Variation of other parameters with depth has not been researched thoroughly. The end bearing capacity does not increase at the same rate as the increasing depth. Figure 7 attempts to formulate the end bearing capacity of a pile with regard to relative density $\left(I_{D}\right)$ and vertical effective stress $\sigma_{v}^{\prime}$ (Randolph et al. [17]).

Table 5. Friction angle $\phi^{\prime}$ vs. $N_{q}$

\begin{tabular}{|l|l|l|l|l|l|l|l|l|l|l|l|l|l|}
\hline$\phi^{\prime}\left[{ }^{\circ}\right]$ & 26 & 28 & 30 & 31 & 32 & 33 & 34 & 35 & 36 & 37 & 38 & 39 & 40 \\
\hline$N_{q}$ for driven piles & 10 & 15 & 21 & 24 & 29 & 35 & 42 & 50 & 62 & 77 & 86 & 120 & 145 \\
\hline$N_{q}$ for bored piles & 5 & 8 & 10 & 12 & 14 & 17 & 21 & 25 & 30 & 38 & 43 & 60 & 72 \\
\hline
\end{tabular}

If water jetting is used, $\phi^{\prime}$ should be limited to $28^{\circ}$. This is because water jets tend to loosen the soil. Hence, higher friction angle values are not warranted.

\subsection{PARAMETERS THAT AFFECT THE END BEARING CAPACITY}

The following parameters affect the end bearing capacity:

(c) Effective stress at pile tip,

(d) Friction angle at pile tip and below $\left(\phi^{\prime}\right)$,

(e) The dilation angle of soil $(\psi)$,

(f) Shear modulus $(G)$,

$(\mathrm{g})$ Poisson's ratio $(v)$.

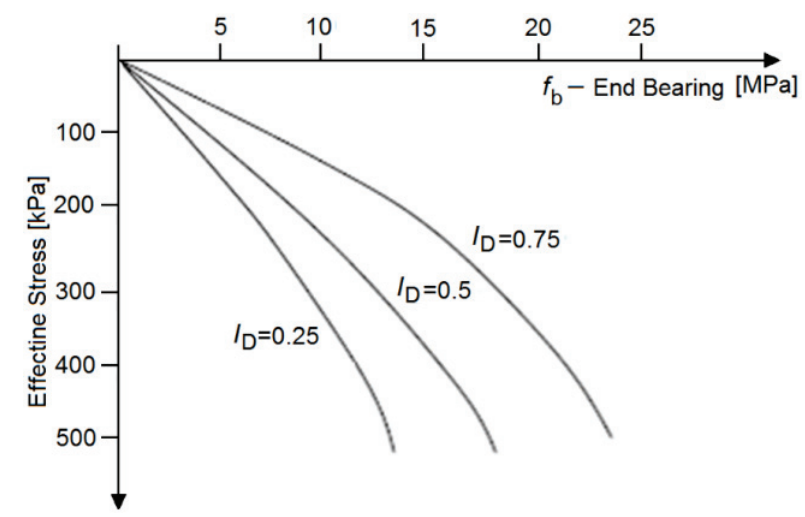

Fig. 7. End bearing capacity of a pile with regard to relative density $\left(I_{D}\right)$ and effective stress (Randolph et al. [27])

Most of these parameters have been bundled into the bearing capacity factor $N_{q}$. It is known that the

\subsection{CRITICAL DEPTH FOR SKIN FRICTION (SANDY SOILS)}

Skin friction should increase with depth and it becomes a constant at a certain depth. This depth was named a critical depth. The typical experimental variation of skin friction with depth in a pile as evidence for critical depth is shown in Fig. 8.

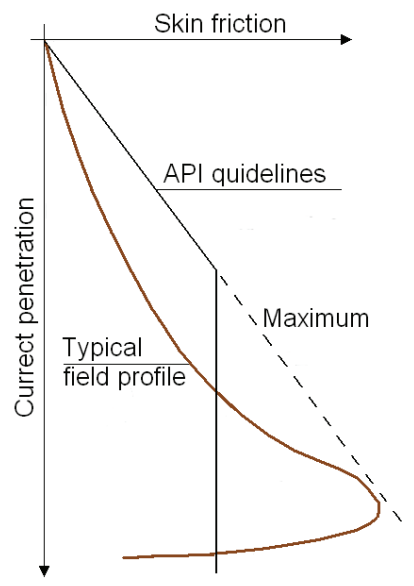

Fig. 8. Variation of skin friction (Randolph et al. [27])

Remarks:

- As one can see, experimental data do not support the old theory with a constant skin friction below the critical depth.

- Skin friction tends to increase with depth and just above the tip of the pile to attain its maximum value. Skin friction would drop rapidly after that.

- Skin friction does not increase linearly with depth as was once believed.

- No satisfactory theory exists at present to explain the field data. 
- Due to lack of a better theory, engineers are still using critical depth theory of the past.

\section{Reasons for limiting skin friction}

The following reasons have been offered to explain why skin friction does not increase with depth indefinitely, as suggested by the skin friction equation:

1. $K$ value is a function of the soil friction angle $\left(\phi^{\prime}\right)$. Friction angle tends to decrease with depth. Hence, $K$ value decreases with depth (Kulhawy [20]).

2. Skin friction equation does not hold true at high stress levels due to readjustment of sand particles.

3. Reduction of local shaft friction with increasing pile depth, see Fig. 9 (Rajapakse [28]).

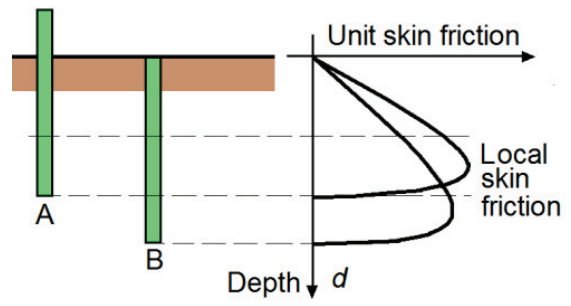

Fig. 9. Example of unit skin friction distribution (Rajapakse [28])

Let us assume that a pile was driven to a depth of $3 \mathrm{~m}$ and unit skin friction was measured at a depth of $1.5 \mathrm{~m}$. Then let us assume that the pile was driven further to a depth of $4.5 \mathrm{~m}$ and unit skin friction was measured at the same depth of $1.5 \mathrm{~m}$. It has been reported that unit skin friction at $1.5 \mathrm{~m}$ is less in the second case.

NAVFAC DM 7.2 gives maximum value of skin friction and end bearing capacity is achieved after 20 diameters within the bearing zone. The following approximations were assumed for the critical depth:

- Critical depth for loose sand $=10 D(D$ is the pile diameter or the width),

- Critical depth for medium dense sand $=15 D$,

- Critical depth for dense sand $=20 D$.

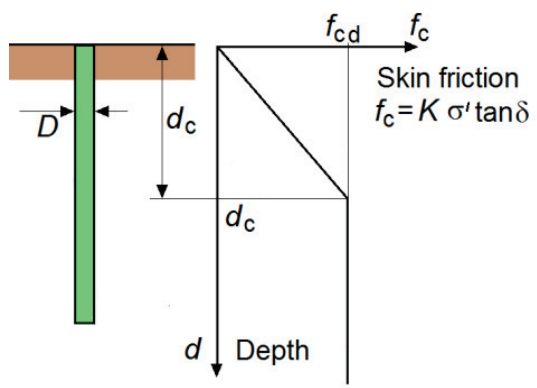

Fig. 10. Critical depth: $d_{c}-$ critical depth, $f_{c d}-$ unit skin friction at critical depth, $f_{c d}=K \quad \sigma_{c}^{\prime} \tan \delta$, $\sigma_{c}^{\prime}-$ effective stress at critical depth

\subsection{CRITICAL DEPTH FOR END BEARING CAPACITY (SANDY SOILS)}

Pile end bearing capacity in sandy soils is related to effective stress. Experimental data indicate that end bearing capacity does not increase with depth indefinitely. Due to lack of a valid theory, engineers use the same critical depth concept adopted for skin friction as forthe end bearing capacity. As shown in Fig. 11, the end bearing capacity was assumed to increase till the critical depth. It is clear that there is a connection between end bearing capacity and skin friction since the same soil properties act in both cases, such as effective stress, friction angle, and relative density. On the other hand, two processes are vastly different in nature.

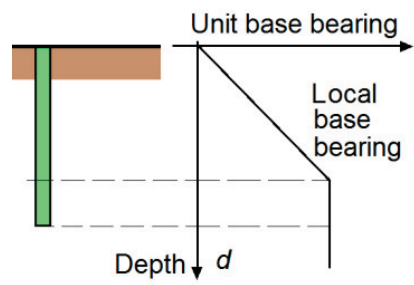

Fig. 11. Unit base bearing capacity and critical depth

The following approximations were assumed for the critical depth within the bearing zone:

- Critical depth for loose sand $=10 D$ ( $D$ is the pile diameter or the width),

- Critical depth for medium dense sand $=15 D$,

- $\quad$ Critical depth for dense sand $=20 D$.

The critical depth concept is a gross approximation that cannot be supported by experimental evidence.

\section{ESTIMATING PILE LOAD CAPACITY BASED ON CPT RESULTS}

\subsection{INTRODUCTION}

Owing to the difficulties and the uncertainties in assessing the pile capacity on the basis of the soil strength-deformation characteristics, the most frequently followed design practice is to refer to the formulae correlating directly the pile capacity components of $q_{b}$ and $q_{s}$ to the results of the prevalent in situ tests. Within the domain of these in situ methods, the cone penetration test (CPT) is one of the most frequently used investigation tools for pile load capacity evaluations. Ever since the first use of CPT in geo- 
technical investigations, research efforts have advanced the very elementary idea of considering it as mini-pile foundation. This has resulted in plethora of correlative relationships being developed between the CPT readings cone resistance $\left(q_{c}\right)$ or more proper corrected cone resistance $\left(q_{t}\right)$, sleeve friction $\left(f_{s}\right)$, and shoulder pore water pressure $\left(u_{2}\right)$ and the pile capacity components of $q_{b}$ and $q_{s}$.

As commonly reported (e.g., Ardalan et al. [2]; Cai et al. [5], [6]), there are two main approaches to accomplish axial pile capacity analysis from CPT data: (a) rational (or indirect) methods and (b) direct methods.

\section{PILE CAPACITY BASE ON CPT PARAMETERS}

\begin{tabular}{|c|c|}
\hline \multicolumn{2}{|c|}{1 - Direct Methods } \\
\hline Pure Empirical Methods & Semi-Fmnirical Methods \\
\hline & \\
\hline $\begin{array}{l}\text { Propositions evaluations } \\
\text { of } q_{\mathrm{s}} \text { and } q_{\mathrm{b}} \text { directly usign }\end{array}$ & $\begin{array}{l}\text { Propositions evaluations } \\
\text { of } q_{\mathrm{s}} \text { and } q_{\mathrm{b}} \text { directly usign }\end{array}$ \\
\hline$q_{\mathrm{c}}\left(\right.$ or $\left.q_{\mathrm{t}}\right)$ and/or $f_{\mathrm{s}}, u_{2}$ & $q_{\mathrm{c}}\left(\right.$ or $\left.q_{\mathrm{t}}\right)$ and/or $f_{\mathrm{s}}$ \\
\hline & $\begin{array}{l}\text { with additional parameters: } \\
\sigma_{\mathrm{r}}, \delta, \phi^{\prime}, K, \sigma_{\mathrm{v} 0}^{\prime}, L, d, s_{\mathrm{u}}, I_{\mathrm{D}}\end{array}$ \\
\hline
\end{tabular}

\begin{tabular}{|c|c|}
\hline \multicolumn{2}{|c|}{2 - Rational (Indirect) Methods } \\
\hline Total Stress Approach & $\frac{1}{\text { Effective Stress Approach }}$ \\
\hline 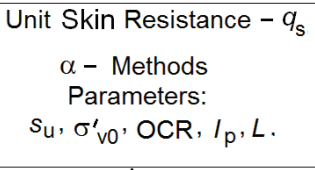 & $\begin{array}{l}\text { Unit Skin Resistance }-q_{\mathrm{s}} \\
\beta \text { - Methods } \\
\text { Parameters: } \\
\sigma_{\mathrm{r}}, \delta, \phi^{\prime}, \text { OCR }, K, \sigma_{\mathrm{v} 0}^{\prime}, L,\end{array}$ \\
\hline $\begin{array}{l}\text { Unit Base Resistance }-q_{\mathrm{b}} \\
\text { Undrained loading, for fine } \\
\text { grained soils, } \\
\text { parameter: } s_{\mathrm{u}}\end{array}$ & $\begin{array}{l}\text { Unit Base Resistance }-q_{\mathrm{b}} \\
\text { Drained loading, for fine } \\
\text { and coarse grained soils, } \\
\text { parameters: } \phi^{\prime}, \sigma_{\mathrm{v} 0}^{\prime}, L, d, I_{\mathrm{D}}\end{array}$ \\
\hline
\end{tabular}

Fig. 12. CPT based evaluations of pile capacity (Niaziand Mayne [24])

- Direct CPT methods - used the similarity of the cone resistance with the pile unit resistances. Some methods may use the cone sleeve friction in determining unit shaft resistance. Several methods modify the resistance values to consider the difference in diameter between the pile and the cone. The influence of mean effective stress, soil compressibility, and rigidity affect the pile and the cone in equal measure, which eliminates the need to supplement the field data with laboratory testing and to calculate intermediate values, such as $K$, and $N_{q}$.

- Pure empirical methods - initial formulations were based solely on cone resistance $\left(q_{c}\right)$ derived from mechanical cone penetrometers. Subsequently, with the introduction of the electrical cone penetrometer, the additional channels measuring sleeve friction $\left(f_{s}\right)$, and porewater pressures ( $u_{1}$ and $u_{2}$ ) were considered.
- Semi-empirical methods - with the purely CPT parameters, the additional estimated parameters are taken into account $\left(\sigma_{r}, \delta, \phi^{\prime}, K, \sigma_{v 0}^{\prime}, L, d, s_{u}, I_{D}\right)$.

- Indirect CPT methods - employ soil parameters, such as friction angle and undrained shear strength obtained from cone data to estimate bearing capacity. The indirect methods apply strip-footing bearing capacity theories, and neglect soil compressibility and strain softening. These methods are rarely used in engineering practice.

\subsection{DIRECT CPT METHODS}

In one viewpoint, the cone penetrometer can be considered as a mini-pile foundation as noted by Ardalan et al. [2] and Eslami and Fellenius (1997). The mean effective stress, compressibility and rigidity of the surrounding soil medium affect the pile and the cone work in a similar manner.This concepthas led to the development of many direct CPT methods.
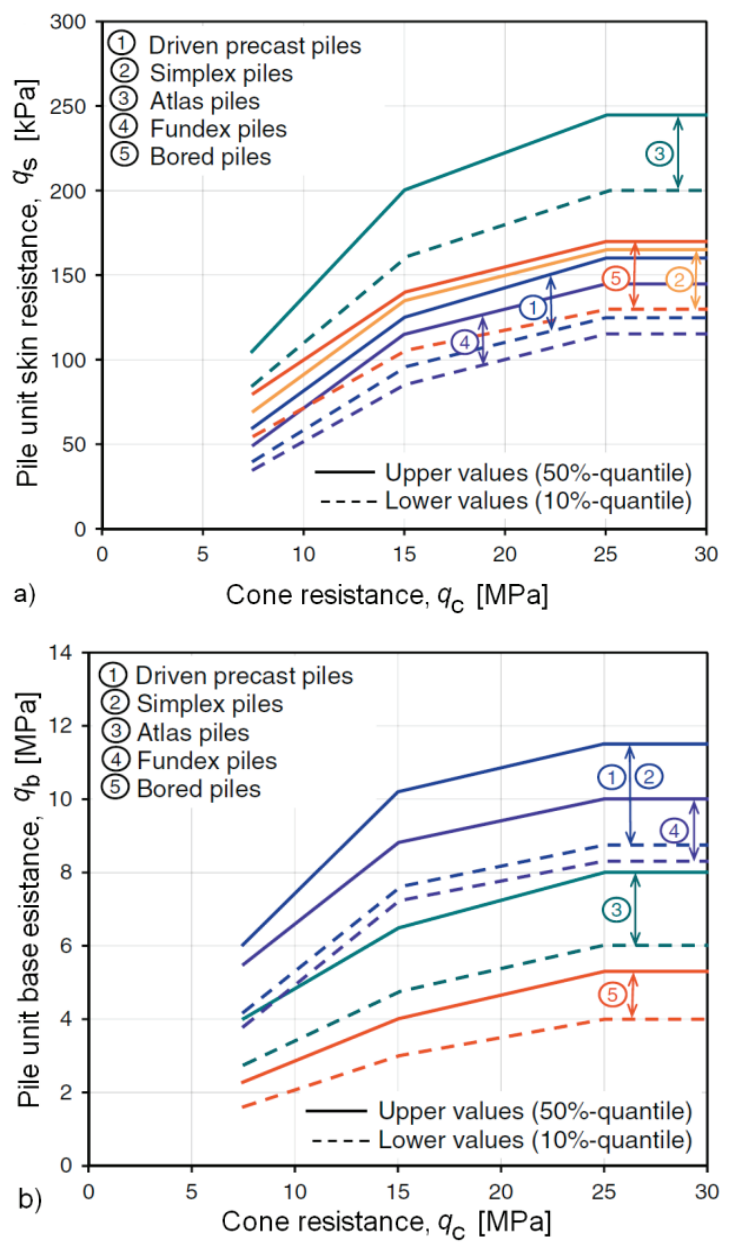

Fig. 13. Upper and lower empirical values of different piles in coarse grained soils for: (a) $q_{s}(z)$; (b) $q_{b}$ (after Kempfert and Becker [17]) 
Unit skin resistance $q_{s}(z)$ and unit base resistance $q_{b}$

Based on the load test database up to 1000 load tests on precast concrete, cast-in-place concrete, steel pipe, screw cast-in-place, and micro piles etc., Kempfert and Becker [17] developed correlations for pile $q_{s}(z)$ and $q_{b}$ from CPT $q_{c}$ and $s_{u}$. Their results, presented in the form of empirically derived charts with upper and lower bound estimates of $q_{s}(z)$ and $q_{b}$ (Fig. 13), have been integrated into the national German recommendations for piles.

\section{Partial embedment reduction factor}

White and Bolton [31] studied, the causes of low values of $q_{b} / q_{c}$ in sand in contrast with $q_{b}=q_{c}$ for steady deep penetration (e.g., cavity expansion solutions and strain path method). They examined a database of 29 load tests on a variety of CE piles (steel pipe piles, Franki piles with enlarged base, and precast square, cylindrical and octagonal concrete piles) and CPT $q_{c}$ data. The low value of $q_{b} / q_{c}$, which forms basis of the apparent scale effect on the diameter, can be attributed topartial embedment in the underlying hard layer (Fig. 14), whereas, partial mobilization was explained by defining failure according to a plunging criterion. They concluded that any reduction of $q_{c}$ when estimating $q_{b}$ of $\mathrm{CE}$ piles in sand should be linked to the above factors rather than pile diameter.

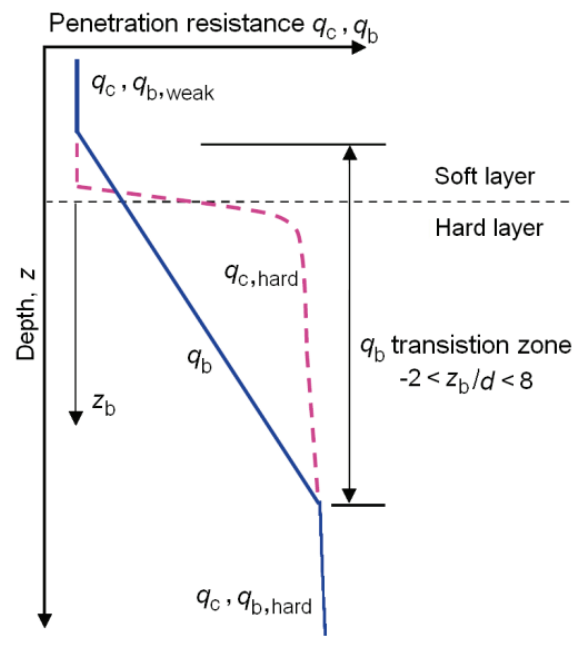

Fig. 14. Partial embedment reduction factor on $q_{b}$ (after White and Bolton [31])

\section{PILE LOAD CAPACITY DETERMINED FROM STATIC LOAD TESTING}

The pile bearing capacity is necessary to verify with the assumption of the design. The most com- mon practice is by means of a static loading test. The capacity is the total ultimate soil resistance of the pile determined from the measured load-settlement behavior. It can be defined as the load for which rapid settlement occurs under sustained or slight increase of the applied load - the pile plunges. This definition is inadequate, however, because large settlement is required for a pile to plunge and is not obtained in the test. Therefore, the pile capacity or ultimate load must be determined by some definition based on the load-settlement data recorded in the test.

Load-displacement curves obtained from axial load tests on pile foundations exhibit differing shapes and resulting conclusions. There is only a single value of load termed "capacity" that is selected from the entire curve for design purposes. Yet, there are at least 45 different criteria available for defining the "axial capacity" (Hirany and Kulhawy [8]). An example of a load test conducted on a $0.76 \mathrm{~m}$ diameter, $16.9 \mathrm{~m}$ long drilled shaft installed at Georgia Institute of Technology is shown in Fig. 15.

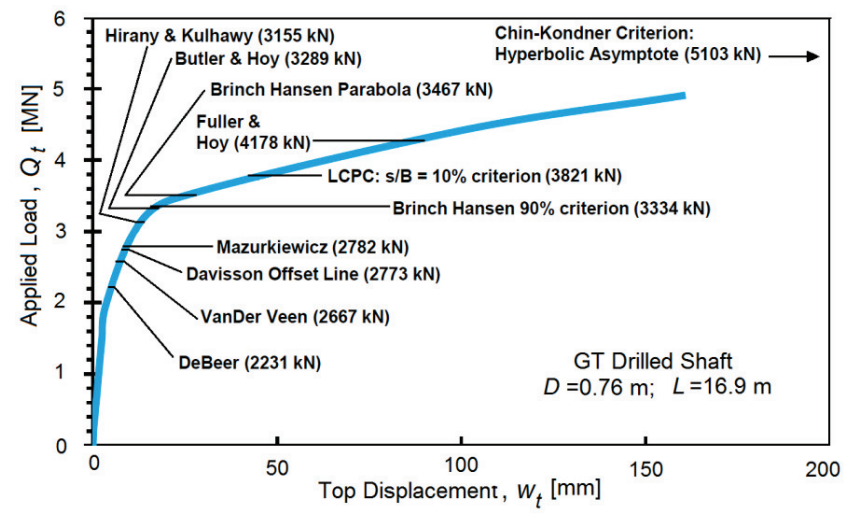

Fig. 15. Comparison of capacity interpretation criteria from axial pile load tests (Hirany and Kulhawy [8])

When interpreting loading tests, the failure condition can be interpreted in several different ways. Tomlinson [30] lists some of the recognized criteria and list disadvantages and advantages of pile tests in general. The main interpreted failure loads correspond to settlements equal to $0.1 d$, where $d$ is the equivalent pile diameter referring to an equivalent circle diameter for square and hexagonal piles. Such definition does not consider the elastic shortening of the pile, which can be substantial for long piles, while it is negligible for short piles. In reality, settlement relates to a movement of superstructure (pile with soil), and it does not relate to the capacity as a soil response to the loads applied to the pile in a static loading test. 


\section{REFERENCES}

[1] American Petroleum Institute, API Recommended Practice for Planning, Designing and Constructing Fixed Off-shore Platforms, API, Washington, DC, 1984.

[2] Ardalan H., Eslami A., Nariman-Zahed N., Piles shaft capacity from CPT and CPTu data by polynomial neural networks and genetic algorithms, Comput. Geotech., 2009, 36, 616-625.

[3] Bond A.J., Schuppener B., Scarpelli G., OrR T.L.L., Eurocode 7: Geotechnical Design Worked examples, Worked examples presented at the Workshop "Eurocode 7: Geotechnical Design" Dublin, 13-14 June 2013.

[4] BudHu M., Soil Mechanics and Foundations, Wiley, Hoboken, New York 1999.

[5] Cai G., Liu S., Tong L., Du G., Assessment of direct CPT and CPTu methods for predicting the ultimate bearing capacity of single piles, Eng. Geol., 2009, 104, 211-222.

[6] Cai G., Liu S., PuPPAla A.J., Reliability assessment of CPTu-based pile capacity predictions in soft clay deposits, Eng. Geol., 2012, 141-142, 84-91.

[7] DNV-OS-J101-2007: Det Norske Veritas. Design of offshore wind turbine structures. October 20007.

[8] Hirany A., Kulhawy F.H., Conduct and interpretation of load tests on drilled shaft foundations, Report EL-5915, 1988,Vol. 1, Electric Power Research Institute, Palo Alto, CA, www.epri.com

[9] Fellenius B.H., Basics of Foundation Design, Electronic Edition, Calgary, Alberta, Canada, T2G 4J3, 2009.

[10] Fleming W.G.K. et al., Piling Engineering, Surrey University Press, New York 1985.

[11] Gwizdala K., Fundamenty palowe. Technologie i obliczenia. Tom 1, Wydawnictwo Naukowe PWN, Warszawa 2010.

[12] Gwizdala K., Fundamenty palowe. Badania i zastosowania. Tom 2, Wydawnictwo Naukowe PWN, Warszawa 2013.

[13] JANBU N., (ed.), Static bearing capacity of friction piles, Proceedings of the 6th European Conference on Soil Mechanics and Foundation Engineering, 1976, Vol. 1.2, 479-488.

[14] Helwany S., Applied soil mechanics with ABAQUS applications, John Wiley \& Sons, Inc., 2007.

[15] Karlsrud K., Clausen C.J.F., Aas P.M., Bearing Capacity of Driven Piles in Clay, the NGI Approach, Proc. Int. Symp. on Frontiers in Offshore Geotechnics, 1. Perth 2005, 775-782.

[16] Karlsrud K., Prediction of load-displacement behavior and capacity of axially loaded piles in clay based on analyses and interpretation of pile load test result, $\mathrm{PhD}$ Thesis, Trondheim, Norwegian University of Science and Technology, 2012.

[17] KeMPFERT H.-G., BECKER P., Axial pile resistance of different pile types based on empirical values, Proceedings of GeoShanghai 2010 deep foundations and geotechnical in situ testing (GSP 205), ASCE, Reston, VA, 2010, 149-154.
[18] Kolk H.J., Van der Velde A., A Reliable Method to Determine Friction Capacity of Piles Driven into Clays, Proc. Offshore Technological Conference, 1996, Vol. 2, Houston, TX.

[19] Kraft L.M., Lyons C.G., State of the Art: Ultimate Axial Capacity of Grouted Piles, Proc. 6th Annual OTC, Houston paper OTC 2081, 1990, 487-503.

[20] Kulhawy F.H. et al., Transmission Line Structure Foundations for Uplift-Compression Loading, Report EL, 2870, Electric Power Research Institute, Palo Alto 1983.

[21] MCClelland B., Design of deep penetration piles for ocean structures, Journal of the Geotechnical Engineering Division, ASCE, 1974, Vol. 100, No. GT7, 705-747.

[22] Meyerhof G.G., Bearing Capacity and Settlement of Pile Foundations, ASCE J. of Geotechnical Eng., 1976, GT3, 195-228.

[23] NAVFAC DM 7.2 (1984): Foundation and Earth Structures, U.S. Department of the Navy.

[24] Niazi F.S., Mayne P.W., Cone Penetration Test Based Direct Methods for Evaluating Static Axial Capacity of Single Piles, Geotechnical and Geological Engineering, 2013, (31), 979-1009.

[25] RandolPh M.F., Wroth C.P., A simple approach to pile design and the evaluation of pile tests, Behavior of Deep Foundations, STP 670, ASTM, West Conshohocken, Pennsylvania, 1979, 484-499.

[26] RandolPh M.F., Design considerations for offshore piles, Proc. of the Conference on Geotechnical Practice in Offshore Engineering, Austin, Texas, 1983, 422-439.

[27] Randolph M.F., Dolwin J., Beck R., Design of Driven Piles in Sand, Geotechnique, 1994, Vol. 44, No. 3, 427-448.

[28] Ruwan Rajapakse, Pile Design and Construction Rules of Thumb, Elsevier, Inc., 2008.

[29] Skempton A.W., Cast-in-situ bored piles in London clay, Geotechnique, 1959, Vol. 9, No. 4, pp. 153-173.

[30] Tomlinson M.J. Pile Design and Construction Practice, Viewpoint Publications, London, 1977, 1981 edition, 1987 edition, 1991 edition, 1994 edition, 1995 edition, 1998 edition, 2008 edition.

[31] White D.J., Bolton M.D., Comparing CPT and pile base resistance in sand, Proc. Inst. Civil Eng. Geotech. Eng., 2005, 158(GE1), 3-14.

[32] Wrana B., Lectures on Soil Mechanics, Wydawnictwo Politechniki Krakowskiej, 2014.

[33] Wrana B., Lectures on Foundations, Wydawnictwo Politechniki Krakowskiej, 2015.

[34] Wysokiński L., KotLicki W., Godlewski T., Projektowanie geotechniczne wedlug Eurokodu 7. Poradnik, Instytut Techniki Budowlanej, Warszawa 2011.

[35] PN-EN 1997-1, Eurocode 7: Geotechnical design - Part 1: General rules. Part 2: Ground investigation and testing. 